\title{
Characterization of refractory organic substances by NEXAFS using a compact $X$-ray source
}

\author{
Julia Sedlmair • Sophie-Charlotte Gleber • \\ Christian Peth • Klaus Mann • Jürgen Niemeyer • \\ Jürgen Thieme
}

Received: 3 November 2010 / Accepted: 11 May 2011 /Published online: 4 June 2011

(C) The Author(s) 2011. This article is published with open access at Springerlink.com

\begin{abstract}
Purpose We present the characterization of environmental samples using near-edge X-ray absorption fine structure (NEXAFS) spectra recorded with an in-house device. We want to point out the feasibility of such an easily accessed complementary technique, if not sometimes alternative to
\end{abstract}

Responsible editor: Caixian Tang

J. Sedlmair $(\bowtie)$

Institute for X-Ray Physics, Georg-August-University Göttingen,

Friedrich-Hund-Platz 1,

37077 Göttingen, Germany

e-mail: jsedlma@gwdg.de

S.-C. Gleber

Argonne National Laboratory,

APS, 9700 S. Cass Avenue, Building 401,

Argonne, IL 60439-4837, USA

C. Peth

Institut für Laser- und Plasmaphysik,

Heinrich-Heine-University Düsseldorf,

Universitätsstr. 1,

40225 Düsseldorf, Germany

\section{K. Mann}

Laser-Laboratorium Göttingen e.V.,

Hans-Adolf-Krebs-Weg 1,

37077 Göttingen, Germany

\section{J. Niemeyer}

Institute for Applied Biotechnology,

Georg-August-University Göttingen,

Marie-Curie-Str. 7 ,

37074 Göttingen, Germany

\section{J. Thieme}

Brookhaven National Laboratory,

NSLS II, Building 817,

Upton, NY 11973, USA
NEXAFS studies performed with synchrotron radiation, as the number of compact setups is increasing.

Materials and methods The experiments were carried out using a laser-driven plasma source. We studied heterogeneous samples like refractory organic substances to demonstrate the potential of NEXAFS spectra, achieved by such an instrument, concerning specimens of high chemical complexity.

Results and discussion From the respective resonance peaks in the spectra, the presence of certain functional groups, such as aromatic or carbonyl groups, is verified, and the elemental composition is estimated. The results of the reference samples are consistent with the literature. For the environmental samples, external influences of the extraction solvent or fertilizers can be determined from the spectra.

Conclusions This could provide the possibility to perform test experiments with samples, which are later studied in more detail with synchrotron light and might as well give an impulse on the broader spread of the application of NEXAFS spectroscopy.

Keywords Compact X-ray spectrometer · Humic substances $\cdot$ NEXAFS

\section{Introduction}

Near-edge X-ray absorption fine structure (NEXAFS) spectroscopy (also X-ray absorption near-edge structure, XANES), using X-radiation of 1-10 nm wavelength, has been established as a useful tool for the characterization of chemical and environmental compounds (Stöhr 1992; Smith et al. 2001; Hitchcock et al. 2005; Brandes et al. 2004; Lehmann et al. 2007; Schumacher et al. 2005). With 
NEXAFS spectroscopy, it is possible to obtain information of the binding situations of elements like carbon, calcium, and sulfur within the samples under investigation (e.g., Schumacher et al. 2005; Mitrea et al. 2008; Thieme et al. 2010; Singh and Gräfe 2010).

The basic principle is the detection of transmitted Xradiation passing through a sample. The transmission is calculated by the Lambert-Beer law $\left(I=I_{0} e^{-\mu(E) \rho d}\right)$, describing the exponential decrease of the incident intensity $I_{0}$ traversing a sample of thickness $d$ and density $\rho$. Via the mass absorption coefficient $\mu$ (E) (CXRO and ALS 2009), the transmission depends on the energy, i.e., the wavelength, of the incident photons. If their energy is high enough to excite electrons in the sample, a jump in the absorption spectrum occurs. At certain energies below and above this absorption edge, some of the electrons are excited to higher atom or molecule orbitals, resulting in modulations in the absorption spectrum around the edge and providing information about the structural (and elemental) composition of a sample (Stöhr 1992; Rehr and Albers 2000).

At first, NEXAFS was used to characterize small, wellknown molecules (Francis and Hitchcock 1992; Ishii and Hitchcock 1987, 1988, Sham et al. 1989, Stöhr 1992) and their orientation and bond lengths. Soon, more complex samples from polymer science were investigated using NEXAFS spectroscopy, see for example Kikuma and Tonner (1996); Urquhart and Ade (2002). Over the recent years, more and more complex heterogeneous samples from biomolecular (Boese et al. 1997; Hitchcock et al. 2005; Benzerara et al. 2006) or environmental (Cody et al. 1998; Braun 2005; Solomon et al. 2009) origin were studied. Especially natural organic matter and soils (Schäfer et al. 2005; Schumacher et al. 2005; Lehmann et al. 2007; Thieme et al. 2010), or particulate matter (Braun et al. 2006, 2007) were subject to such studies, by which valuable information about the chemical composition and functional groups and also their change due to photolysis, temperature, and so on could be gained.

Such spectroscopic investigations are most often carried out at synchrotron radiation facilities, which produce radiation of very high brilliance and intensity over a very broad wavelength range. Due to the high amount of information obtainable by these experiments, a high demand exits for measuring time at these setups. Sometimes, this may lead to rather high waiting times before the measurements can be performed.

To elucidate whether the samples under investigation are suited for NEXAFS, it would be desirable, if a setup existed that would allow preliminary measurements. That way, appropriate sample preparation techniques, the sample holder equipment, and the sample storage could be tested, or improved, too. In addition, new approaches for the evaluation of the obtained spectra could be developed. This approach would drastically reduce the amount of time required at the synchrotrons leading to a much higher sample throughput and thus to a reduction of waiting time.

Apart from potential improvements of the preparation of synchrotron experiments, a tabletop spectrometer could have other possible fields of application. If such an instrument is for instance incorporated into a soil science laboratory, kinetic measurements would be feasible. Experiments investigating the interactions of model compounds like distinct proteins (Pagel-Wieder et al. 2007), leaching experiments, or the change of extracted substances depending on extraction time or solvent would be realizable within a short measuring time. With an instrument on site, experiments would be quickly repeatable also adding to statistical context, which is important for instance, to test heterogeneity in the field.

In the last years, laser-driven plasma sources for soft Xradiation have been developed (Peth et al. 2008; Jansson et al. 2005; Fiedorowicz 2005). It has been demonstrated that applications such as X-ray microscopy (Hertz et al. 2009) or spectroscopy (Vogt et al. 2004), which were restricted to synchrotron experiments could be realized. Apart from plasma sources, also other tabletop setups operating with high harmonic generation (Seres et al. 2007; Zepf et al. 2007) or X-ray lasers (Wang et al. 2006) generate Xradiation of high brilliance. Laser plasmas are attractive compact X-ray sources due to their small size, high spatial stability and high brightness, and/or high flux. In the following, we present the application of a tabletop instrument to study environmental samples using soft Xrays with photon energies below $1 \mathrm{keV}$. In previous experiments with the same instrument, polymers have been studied and the outcome was related to synchrotron measurements (Nováková et al. 2008). In Sedlmair et al. (2009), it was demonstrated that the effect of different extraction methods is also detectable using this setup. Here, a more detailed study is shown. The experiments are combined with an empirical analysis to quantitatively assess complex heterogeneous systems like refractory organic substances

\section{Experimental section}

\subsection{Samples and preparation}

We analyzed six different samples. The first two were used as reference samples: a polyimide foil (PMDA/ODA, PI 2545, HD Microsystems, $d=200 \mathrm{~nm}$ ) and a humic acid (H16752, purchased from Sigma Aldrich). The other four samples were: two HAs (humic acids) extracted from a gleyic chernozem from an Ah horizon (German taxonomy: Schwarzerde, from Rosdorf near Göttingen, Germany) 
(Scheffer and Schachtschabel 2010; Ahl et al. 2007), by Na-pyrophosphate solution $(\mathrm{pH}=7.0)$, referred to as HA1, or by sodium hydroxide solution, referred to as HA2, respectively. An aquatic fulvic acid from Lake Hohloh in the Black Forrest obtained by sorption on a resin (XAD), according to the procedure of the IHSS (International Humic Substances Society). The last sample is a size fraction of a luvisol soil with a low content in organic matter in general (again from the Göttingen area).

Apart from the polyimide (PI) foils, which did not require further sample preparation, the basic procedure was the following: the lyophilized original substances were redissolved in ultrapure water (Millipore) as $1 \%$ stock solutions; if necessary, these were diluted further. Glass vessels ( $2 \mathrm{ml}$, Eppendorf), containing the suspensions, were treated with ultrasound for several minutes. Afterwards, we waited $(\sim 30 \mathrm{~min}$.) for the larger particles to settle down before $1-2 \mu \mathrm{l}$ of the supernatant of these suspensions were dropped on a $\mathrm{Si}_{3} \mathrm{~N}_{4}$ membrane (membrane window $1.5 \times$ $1.5 \mathrm{~mm}^{2}, 100-\mathrm{nm}$ thick; frame $5 \times 5 \mathrm{~mm}^{2}, 200-\mu \mathrm{m}$ thick, from Silson Ltd., Northampton, England). After evaporation of the water, the membrane with the dried sample was ready to be mounted on the sample holder and positioned in the tabletop NEXAFS spectrometer. In contrast to polymer samples, samples of natural origin are not of high purity. Therefore, the $\mathrm{Si}_{3} \mathrm{~N}_{4}$ membranes were not subject to any further cleaning procedures, apart from the fact that the membranes are packed under clean atmosphere. To determine the fraction of the membrane to the recorded spectra, empty membranes were measured, too.

Due to the size of the area, from which the transmitted light is detected $(100 \mu \mathrm{m} \times 2.3 \mathrm{~mm})$, variations in chemical composition are averaged out. Typically, the test samples showed thicknesses $d$ of a few hundred nanometers. This can be calculated from the incoming signal using $\left(d=\frac{o D_{1}-\left(E_{2} / E_{1}\right)^{3} o D_{2}}{\mu_{1}-\left(E_{2} / E_{1}\right)^{3} \mu_{2}}\right)$ with optical density oD $(\mathrm{oD}=-\ln$ $\left(\frac{I}{I_{0}}\right)$ ) $\begin{gathered}\mu_{1}-\left(E_{2} / E_{1}\right)^{3} \mu_{2} \\ \text { and mass absorption coefficient } \mu \text { measured at two }\end{gathered}$ different energies E well below (2) and above (1) an absorption edge (Kaznacheyev et al. 2002).

\subsection{Instrumentation}

The instrumental setup of the NEXAFS spectrometer using a laser-plasma source for generating soft $\mathrm{X}$-radiation is described in detail by Peth et al. (2008).

An outline of the setup is depicted in Fig. 1. The major components, source, object holder, and spectrometer, are connected with flanges. The distance between the plasma source and the sample is about $220 \mathrm{~mm}$ followed by an opening wit a diameter of $5 \mathrm{~mm}$ between source and sample stage, also in vacuum. The distance between the sample and the entrance slit of the spectrometer is about $425 \mathrm{~mm}$.
The plasma source, a pulsed Krypton gas target, emits broadband radiation in the spectral range of the water window (280-530 eV, Kr XXV - Kr XXVI). The source radiates isotropically into a full solid angle of $4 \pi$; therefore, the sample is fully illuminated. However, the width of the detector of the spectrometer and the entrance slit $(100 \mu \mathrm{m})$ limit the acceptance; thus, only the transmitted intensity of a sample region of $(100 \mu \mathrm{m} \times 2.3 \mathrm{~mm})$ is detected. The XUV spectrometer consists of an aberration corrected flatfield grating (2,400 lines per millimeter) working in reflection, and a thinned backside illuminated CCD camera. The reference signal $I_{0}$ is recorded separately, but due to the stability of the plasma source (deviation of spectra $<5 \%$ in previous experiments (Peth 2008; Nováková et al. 2008)), this is not a drawback. The signal is automatically converted to optical density by the software using the Lambert-Beer equation, cf. Section 1.

\subsection{Analysis of the spectra}

Before fitting, the spectra were smoothed using a standard algorithm (Golay-Savitzky algorithm). A linear pre-edge background was subtracted from each spectrum, representing the decay, which is usually observed in X-ray absorption spectra (Stöhr 1992) and defining the zero line. Because for the analysis, the relations of the peaks within one spectrum are regarded, renormalization was done by setting the highest point to 1 , making the qualitative comparison between the spectra easier. The analysis of the NEXAFS spectra was carried out using SpecFit, an IDLprogram (Interactive Data Language) developed within our group (Gleber et al. 2003).

To fit the spectrum of a heterogeneous sample of mainly unknown chemical composition, two different approaches were combined. Firstly, we localized the positions of the peaks from the minima of the second derivative of a spectrum, with respect to the energy, as shown in Fig. 2 and the inset. Secondly, we took advantage of the fact that published NEXAFS-spectra of many chemical compounds already exist, e.g., (Smith et al. 2001; Hitchcock et al. 2005; Dhez et al. 2003; Shober et al. 2006; Hitchcock 2009; Ishii and Hitchcock 1988; Cooney and Urquhart 2004; Mitrea et al. 2008; Solomon et al. 2005, 2009). We compared these with the positions gained from the derivatives. The peaks expected from transitions to unoccupied orbitals were added, such as $\sigma^{*}{ }_{\mathrm{C}-\mathrm{N}}, \sigma^{*}{ }_{\mathrm{C}-\mathrm{S}}$, or phenolic $\pi^{*}{ }_{\mathrm{C}=\mathrm{C}}$, which were not noticeable from the spectrum or its derivatives in the first place, with the most probable positions (e.g., from Samant et al. (1996), Hitchcock (2009), Cooney and Urquhart (2004), Dhez et al. (2003), and Kaznacheyev et al. (2002)) as starting points for the fitting algorithm.

Because of their asymmetrical shape, the peaks cannot be fitted exactly with a Gaussian curve (Dhez et al. 2003). 
Fig. 1 Sketch (not to scale) of the instrumental setup of the laser-plasma XUV source used for recording the NEXAFS spectra. The setup can be used in a transmission and reflection geometry depending on the sample and experiment. The instrument has been developed up at the Laser-Laboratorium in Göttingen and is described in detail in Peth et al. (2008)

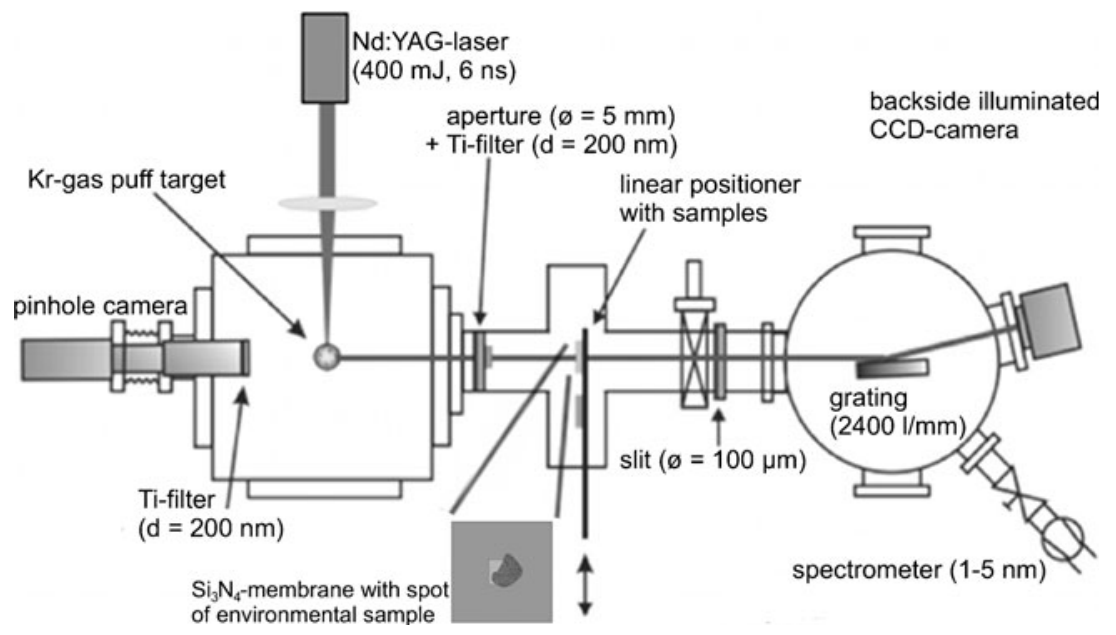

Often, NEXAFS spectra are fitted using Gaussian curves for the peaks and an arctangent function to simulate the absorption edge. However, as seen from NEXAFS spectra of small, well-understood molecules (Ishii and Hitchcock 1987, 1988; Sham et al. 1989; Cooney and Urquhart 2004; Kolczewski et al. 2006; Bâldea et al. 2007; Solomon et al. 2009), shifts of peak positions and absorption edges occur, depending on, e.g., the chemical environment, the substrate, or the state of aggregation. Furthermore, the functional and other subgroups in such large compositions are regarded as independent units. But each of these units has its ionization point at another energy, as known from the literature (Francis and Hitchcock 1992; Ishii and Hitchcock 1987,
1988; Sham et al. 1989; Stöhr 1992; Kikuma and Tonner 1996). Thus, due to a mix of chemistries leading to chemical shifts of the core level, the arctangent for large and complex molecules like environmental samples would be very broad, and thereby dominate the fit of the spectra and submerging the Gaussian curves, see Fig. 3 (arrows). In addition to that, it is not trivial to determine the exact location of the arctangent (Stöhr 1992). To account for this and for the asymmetry of the peaks, we used a combination of Gaussian, Lorentzian, and arctangent curve for every peak. It has already been stated by other authors that the deconvolution of NEXAFS spectra by Gaussian (and/or Lorentzian) curves and an absorption edge is still subject to
Fig. 2 NEXAFS spectrum of humic acid from Sigma Aldrich. The assignments were chosen by comparing with data from published NEXAFS data. The spectrum is used to prove, whether quantitative statements concerning elemental composition can be made

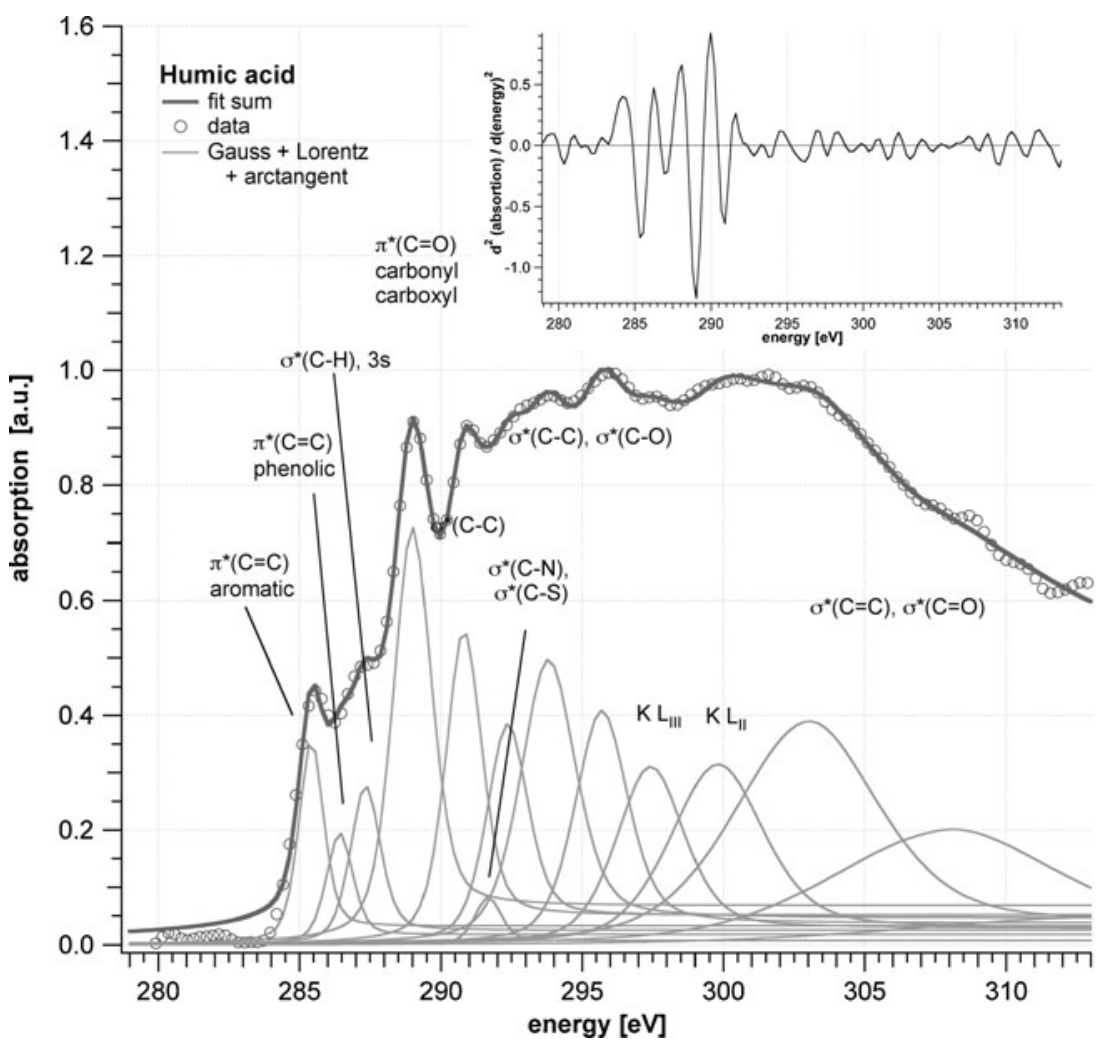


Fig. 3 Spectrum of polyimide foil at CK edge, a with evaluation curves as used for the experiments presented here, b fitted assuming one global absorption edge. The inset in a shows the structural formula of polyimide. The assignment of the peaks with increasing energy results from comparison with published results and the differentiation of the measured data, and is presented in Table 2
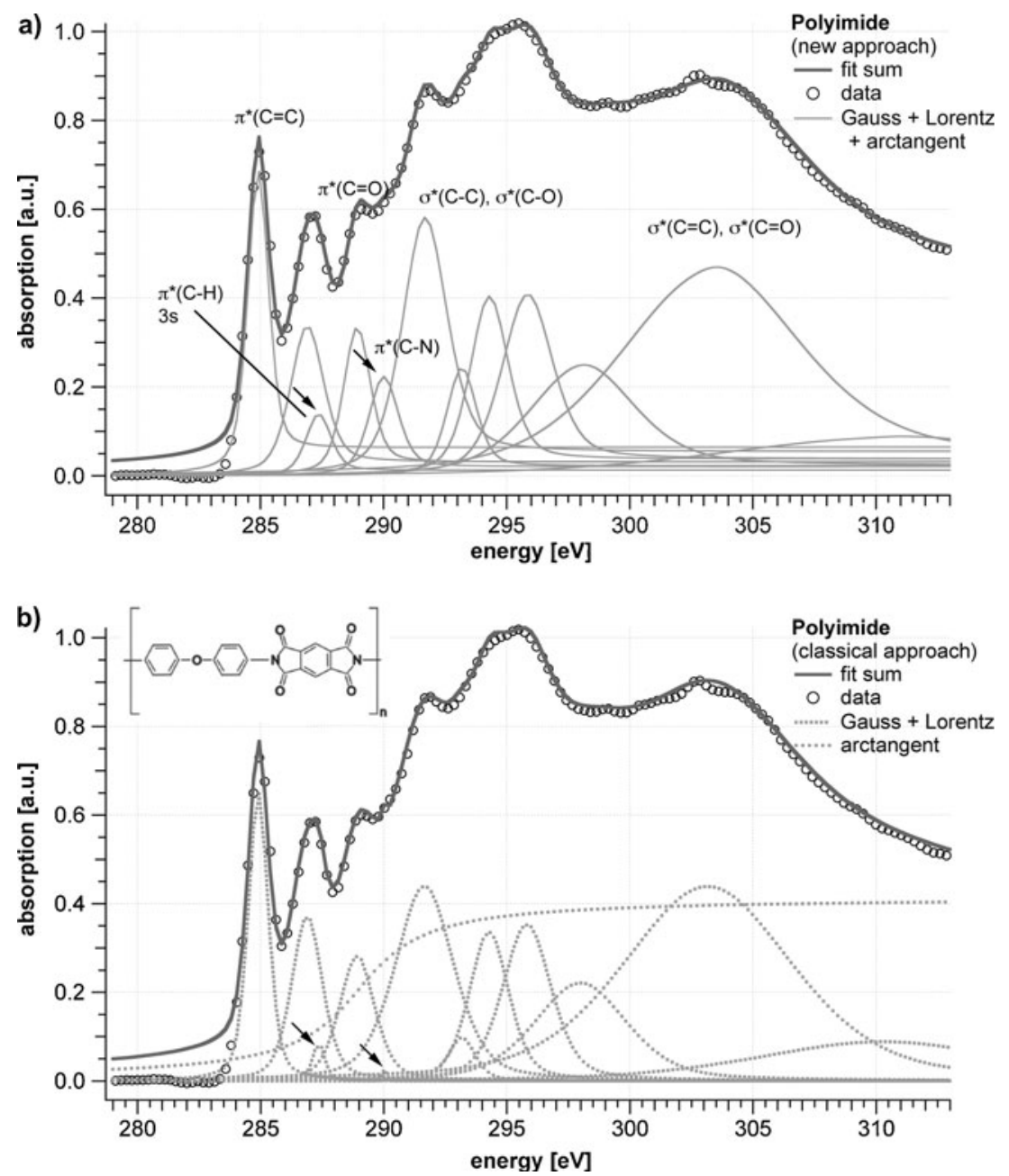

discussions (Stöhr 1992; Cody et al. 1995; Kaznacheyev et al. 2002; Dhez et al. 2003).

Handling the complexity of the sampled data, we had to make reasonable assumptions concerning the parameters of the three curves that were assigned to every peak in to achieve consistent results. The ratio of Gaussian to Lorentzian curve was set to 0.6; the latter accounts for the widening of the peaks due to intrinsic properties of the instrument. The width of the arctangent was set to $0.8 \mathrm{eV}$ and its inflection point to the same energy of the respective peak. The relative height of the arctangent was set to be 0.1 , which we estimated via the attenuation length (CXRO 2010).

\section{Results and discussion}

\subsection{Reference samples}

In the course of analyzing the reference spectra, the empirical approach to estimate the elemental composition of the samples is explained, too. The polyimide foil was useful as the first reference sample, since its structure is sufficiently complex to test our approach of referring to published NEXAFS data from polymer science to find the correct assignment of the peaks in addition to the mathematical strategy using the second derivatives. Polyimides are synthetic polymers, consisting of well-defined building blocks (inset in Fig. 3a), from which we calculated the elemental composition (Table 1). The main constituent, the imide group, is part of every polyimide, but the moieties of the different polyimides vary. The recorded spectrum of the polyimide foil used here, shown in Fig. 3, is quite well comparable to NEXAFS spectra of other polyimides (Stöhr et al. 2001; Samant et al. 1996). The very prominent resonances of the aromatic rings at $284.9 \mathrm{eV}$ (benzene) and $286.9 \mathrm{eV}$ (phenol), the peak of the carboxyl group $(288.9 \mathrm{eV})$ and the peaks of the transition to the $\sigma^{*}$-orbitals around 291 and $295 \mathrm{eV}$ are characteristic for these polymers.

The bonding environment is probed resulting into peaks in the spectra. The heights and widths of these resonance peaks are proportional to the number of transitions in the sample and allow an approximation of elemental composition of the sample. A similar approach works for NEXAFS spectra of sulfur and has also been applied to XPS (X-ray 
Table 1 Elemental composition of the analyzed samples, HA from Sigma Aldrich, three HS, and a soil, shown in Figs. 2, 3 a, and 4

\begin{tabular}{|c|c|c|c|c|c|c|c|}
\hline \multirow[t]{2}{*}{ Sample } & \multirow[t]{2}{*}{ Method } & \multirow[t]{2}{*}{ Comment } & \multicolumn{5}{|c|}{ Composition (\%) } \\
\hline & & & $\mathrm{C}$ & $\mathrm{H}$ & $\mathrm{O}$ & $\mathrm{N}$ & $\mathrm{S}$ \\
\hline \multirow[t]{3}{*}{ Polyimide foil } & Calculated & & 69.1 & 2.6 & 20.9 & 7.3 & - \\
\hline & NEXAFS + SpecFit & cf. Fig. 2a & 67.3 & 1.3 & 26.8 & 4.7 & - \\
\hline & & cf. Fig. $2 b$ & 70.3 & 0.5 & 29.1 & 0.2 & - \\
\hline \multirow[t]{5}{*}{ HA (Sigma) } & Analytical & Sigma Aldrich & 54.7 & 4.4 & 36.3 & 0.8 & 3.8 \\
\hline & CONS & Monteil-Rivera et al. (2000) & 64.0 & n.n. & 30.6 & 1.0 & 4.4 \\
\hline & XPS & & 68.7 & n.n. & 25.9 & 1.1 & 4.3 \\
\hline & $\mathrm{CP} / \mathrm{MAS}{ }^{13} \mathrm{C} \mathrm{NMR}$ & Sierra et al. (2005) & 69.4 & 2.7 & 21.9 & n.n. & 6.1 \\
\hline & NEXAFS+SpecFit & & 59.4 & 3.1 & 36.0 & 1.6 & \\
\hline \multirow[t]{4}{*}{ Environmental samples } & NEXAFS + SpecFit & HA1 & 62.9 & 2.3 & 31.4 & 3.4 & \\
\hline & & HA2 & 55.6 & 3.2 & 37.7 & 3.6 & \\
\hline & & FA & 55.2 & 3.3 & 37.7 & 3.6 & \\
\hline & & Luvisol & 54.6 & 3.5 & 40.1 & 1.8 & \\
\hline
\end{tabular}

For the values gained from the evaluation with SpecFit from the NEXAFS data, the percentages in elemental composition have been calculated by setting the sum of the five main contributors to $100 \%$

photoelectron spectroscopy) data (Bubert et al. 2000). For the analysis, we hence assumed that the area under a Gaussian curve assigned to a resonance is proportional to the frequency of occurrence of this binding form of the studied element (Xia et al. 1998; Huffman et al. 1991; Cody et al. 1998; di Stasio and Braun 2006), making it possible to approximate the composition of the bound elements. To do so, the areas of the peaks were added up, and the sum was set to $100 \%$ in the sample. For the PI and the HA, these values are collated in Table 2. By summing up the respective percentages of the transitions to the single $(\sigma)$ and double $(\pi)$ bond orbitals of the same kind, an estimate of the elemental composition in the organic part of the studied sample was achieved. Peaks assigned to more than one transition were counted in equal parts to the relative component, e.g., $50 \%$ of the area under the polyimide peak at $287.36 \mathrm{eV}\left(1 \mathrm{~s} \rightarrow \sigma^{*}{ }_{\mathrm{C}-\mathrm{H}}, 3 \mathrm{~s}\right)$ was added to the amount of C, $50 \%$ to the amount of $\mathrm{H}$.

Since the spectral features not only comprise of contributions of the transitions noted in the second column in Table 2, only the most probable transitions, according to literature are used for assignment of the peaks. The values for the elemental compositions should thus be considered as maximum content. In particular, the amounts of $\mathrm{N}$ and $\mathrm{S}$ are affected, since they are estimated from the assigned $\sigma^{*}{ }_{\mathrm{C}-\mathrm{N}}$ and $\sigma^{*}{ }_{\mathrm{C}-\mathrm{S}}$ resonances.

For the calculations, the peaks of the potassium $\mathrm{L}_{\mathrm{II}, \mathrm{III}}$ edges have not been taken into account. At energies above $300 \mathrm{eV}$, the transitions to $\sigma^{*} \mathrm{C}=\mathrm{C}$ and $\sigma^{*} \mathrm{C}=\mathrm{O}$ are located. However, the contribution of the double bond compounds has already been accounted for from the $\pi^{*}$ orbitals, thus, they were left out of the estimation, too.

Often, NEXAFS spectra are evaluated by fitting the peaks with Gaussian (and Lorentzian) curves and using one broad global arctangent function for the absorption edge (Dhez et al. 2003; Mitrea et al. 2008; Huffman et al. 1991). To demonstrate the advantage of our approach, we also used this procedure to evaluate the polyimide foil. The comparison (see Table 1) of the results shows that the elemental composition is no longer assessable. This is mainly due to the resonances around $290 \mathrm{eV}$ now being significantly smaller (arrows at $1 \mathrm{~s} \rightarrow \sigma^{*}{ }_{\mathrm{C}-\mathrm{N}}$ and $\sigma^{*}{ }_{\mathrm{C}-\mathrm{C}}$ in Fig. 3).

The information yielded by the polyimide spectrum was helpful to characterize the second reference sample, a wellinvestigated HA standard sample (Monteil-Rivera et al. 2000; Sierra et al. 2005; Plucinski et al. 2007; Rodrigues et al. 2008). The spectrum is displayed in Fig. 2 with the assignments of the peaks depicted in more detail. The relation of the peak heights within the spectrum is characteristic for this sample, as the comparison with HA in the following paragraph and from literature (Solomon et al. 2005, 2009) shows. The inset shows the second derivative of the absorption with respect to the energy. The minima of the derivative were used to determine the locations of most of the peaks in the spectrum of the HA, as mentioned before. This procedure has also been applied to the other spectra. The middle part of Table 1 shows the outcome of our study on the HA from Sigma Aldrich in comparison with published data from Monteil-Rivera et al. (2000) and Rodrigues et al. (2008). Our approximation of the elemental compositions yields values close to the analytical data, directly taken from the supply company, Sigma Aldrich. In Monteil-Rivera et al. (2000), the elemental composition has been determined with an elemental analyzer and with X-ray photoelectron spectroscopy (XPS). Sierra et al. (2005) used solid-state CP/MAS ${ }^{13} \mathrm{C}$ NMR spectroscopy $(\mathrm{CP}=$ cross polarization, $\mathrm{MAS}=$ magic angle spinning) for the chemical analysis of this HA sample. 
Table 2 Energy positions and assignments of features in the C 1s NEXAFS spectrum of polyimide in Fig. 3a), the humic acid purchased from Sigma in Fig. 2, and the luvisol; the last two features have not been taken into account to calculate the elemental composition in Table 1

\begin{tabular}{|c|c|c|c|c|}
\hline Sample & Position (eV) & $1 \mathrm{~s} \rightarrow($ orbital $)$ & Main character & Analysis (\%) \\
\hline \multirow[t]{12}{*}{ Polyimide foil } & 284.9 & $\pi^{*} \mathrm{C}=\mathrm{C}$ & Aromatic & 10.2 \\
\hline & 286.9 & $\pi_{\mathrm{C}=\mathrm{C}}^{*}$ & Phenolic & 8.0 \\
\hline & 287.4 & $\sigma^{*}{ }_{\mathrm{C}-\mathrm{H}}, 3 \mathrm{~s}$ & Carbohydrates & 2.5 \\
\hline & 288.9 & $\pi_{\mathrm{C}=\mathrm{O}}^{*}$ & Carbonyl & 6.4 \\
\hline & 290.0 & $\sigma^{*}{ }_{\mathrm{C}-\mathrm{N}}$ & Imide & 4.7 \\
\hline & 291.7 & $\sigma^{*}{ }_{\mathrm{C}-\mathrm{C}}$ & & 18.6 \\
\hline & 293.2 & $\sigma^{*}{ }_{C-C}$ & & 5.1 \\
\hline & 294.3 & $\sigma^{*}{ }_{\mathrm{C}-\mathrm{O}}$ & & 11.1 \\
\hline & 295.8 & $\sigma^{*}{ }_{C-C}, 4 p$ & & 14.8 \\
\hline & 298.0 & $\sigma^{*}{ }_{\mathrm{C}-\mathrm{O}}, \sigma^{*}{ }_{\mathrm{C}-\mathrm{C}}$ & & 18.6 \\
\hline & 303.2 & $\sigma^{*}{ }_{\mathrm{C}=\mathrm{C}}$ & & \\
\hline & 310.3 & $\sigma^{*}{ }_{\mathrm{C}=\mathrm{C}}, \sigma^{*}{ }_{\mathrm{C}=\mathrm{O}}$ & & \\
\hline \multirow[t]{14}{*}{ HA (Sigma) } & 285.4 & $\pi_{\mathrm{C}=\mathrm{C}}^{*}$ & Aromatic & 6.5 \\
\hline & 286.4 & $\pi^{*}{ }_{\mathrm{C}=\mathrm{C}}$ & Phenolic & 3.8 \\
\hline & 287.3 & $\sigma^{*}{ }_{\mathrm{C}-\mathrm{H}}, 3 \mathrm{~s}$ & Carbohydrates, aliphatic $\mathrm{C}$, phenolic & 6.1 \\
\hline & 289.0 & $\pi^{*} \mathrm{C}=\mathrm{O}$ & Carbonyl, carboxyl, alkyl-C & 20.3 \\
\hline & 290.8 & Ryd, $4 p, 3 p$ & Rydberg, alkyl-C & 14.5 \\
\hline & 291.7 & $\sigma^{*}{ }_{\mathrm{C}-\mathrm{N}}, \sigma^{*}{ }_{\mathrm{C}-\mathrm{S}}$ & & 1.6 \\
\hline & 292.3 & $\sigma^{*}{ }_{\mathrm{C}-\mathrm{O}}, \sigma^{*}{ }_{\mathrm{C}-\mathrm{C}}$ & & 11.3 \\
\hline & 293.8 & $\sigma^{*}{ }_{\mathrm{C}-\mathrm{O}}, \sigma^{*}{ }_{\mathrm{C}-\mathrm{C}}$ & & 20.1 \\
\hline & 295.7 & $\sigma^{*}{ }_{C-C}$, Ryd & & 15.9 \\
\hline & 297.4 & $\mathrm{~K} \mathrm{~L}_{\text {III }}$ & Potassium & \\
\hline & 299.7 & $\mathrm{~K} \mathrm{~L}_{\mathrm{II}}$ & Potassium & \\
\hline & 302.8 & $\sigma^{*} \mathrm{C}=\mathrm{C}$ & & \\
\hline & 307.7 & $\sigma^{*}{ }_{\mathrm{C}=\mathrm{C}}, \sigma^{*}{ }_{\mathrm{C}=\mathrm{O}}$ & & \\
\hline & 313.0 & $\sigma^{*}{ }_{\mathrm{C}=\mathrm{C}}, \sigma^{*}{ }_{\mathrm{C}=\mathrm{O}}$ & & \\
\hline \multirow[t]{14}{*}{ Luvisol } & 284.9 & $\pi^{*} \mathrm{C}=\mathrm{C}$ & Aromatic, phenol & 5.3 \\
\hline & 286.7 & $\sigma^{*}{ }_{\mathrm{C}-\mathrm{H}}, 3 \mathrm{~s}, \pi^{*}{ }_{\mathrm{C}=\mathrm{C}}$ & Carbohydrates, aliphatic $\mathrm{C}$, phenolic & 4.7 \\
\hline & 288.2 & $\pi^{*} \mathrm{C}=\mathrm{O}$ & Carbonyl, carboxyl & 18.9 \\
\hline & 289.7 & $3 \mathrm{p}, \sigma^{*}{ }_{\mathrm{C}-\mathrm{C}}, \sigma^{*}{ }_{\mathrm{C}-\mathrm{H}}$ & Alkyl-C & 5.7 \\
\hline & 290.7 & $\sigma^{*}{ }_{\mathrm{C}-\mathrm{N}}, \sigma^{*}{ }_{\mathrm{C}-\mathrm{S}}$ & & 1.8 \\
\hline & 291.4 & $\sigma^{*}{ }_{C-C}$, Ryd & & 21.2 \\
\hline & 293.8 & $\sigma^{*}{ }_{\mathrm{C}-\mathrm{O}}, \sigma^{*}{ }_{\mathrm{C}-\mathrm{C}}$ & & 30.1 \\
\hline & 296.0 & $\sigma^{*}{ }_{\mathrm{C}-\mathrm{O}}, \sigma^{*}{ }_{\mathrm{C}-\mathrm{C}}$ & & 12.4 \\
\hline & 297.2 & $\mathrm{~K} \mathrm{~L}_{\mathrm{III}}$ & Potassium & \\
\hline & 299.9 & $\mathrm{~K} \mathrm{~L}_{\mathrm{II}}$ & Potassium & \\
\hline & 301.5 & $\sigma^{*}{ }_{\mathrm{C}=\mathrm{C}}$ & & \\
\hline & 303.0 & $\sigma^{*}=\mathrm{O}$ & & \\
\hline & 305.9 & $\sigma^{*}{ }_{\mathrm{C}=\mathrm{C}}, \sigma^{*}{ }_{\mathrm{C}=\mathrm{O}}$ & & \\
\hline & 310.0 & $\sigma^{*} \mathrm{C}=\mathrm{C}, \sigma^{*} \mathrm{C}=\mathrm{O}$ & & \\
\hline
\end{tabular}

\subsection{Environmental samples}

With the results obtained from the reference samples, we were able to analyze environmental samples of unknown composition. The spectra of the measurements are depicted in Fig. 4. The estimation of the chemical composition is shown in Table 1.
The spectra in Fig. 4a, b stem from HA of the identical gleyic chernozem, but were extracted with different methods (cf. Section 2.1). For HA1 (see Fig. 4a), Napyrophosphate was used, while HA2 (see Fig. 4b) was extracted with $\mathrm{NaOH}$. From the NEXAFS, experiment the effect of these different methods becomes clear. HA1 exhibits a strong absorption around 285-286 eV, where 

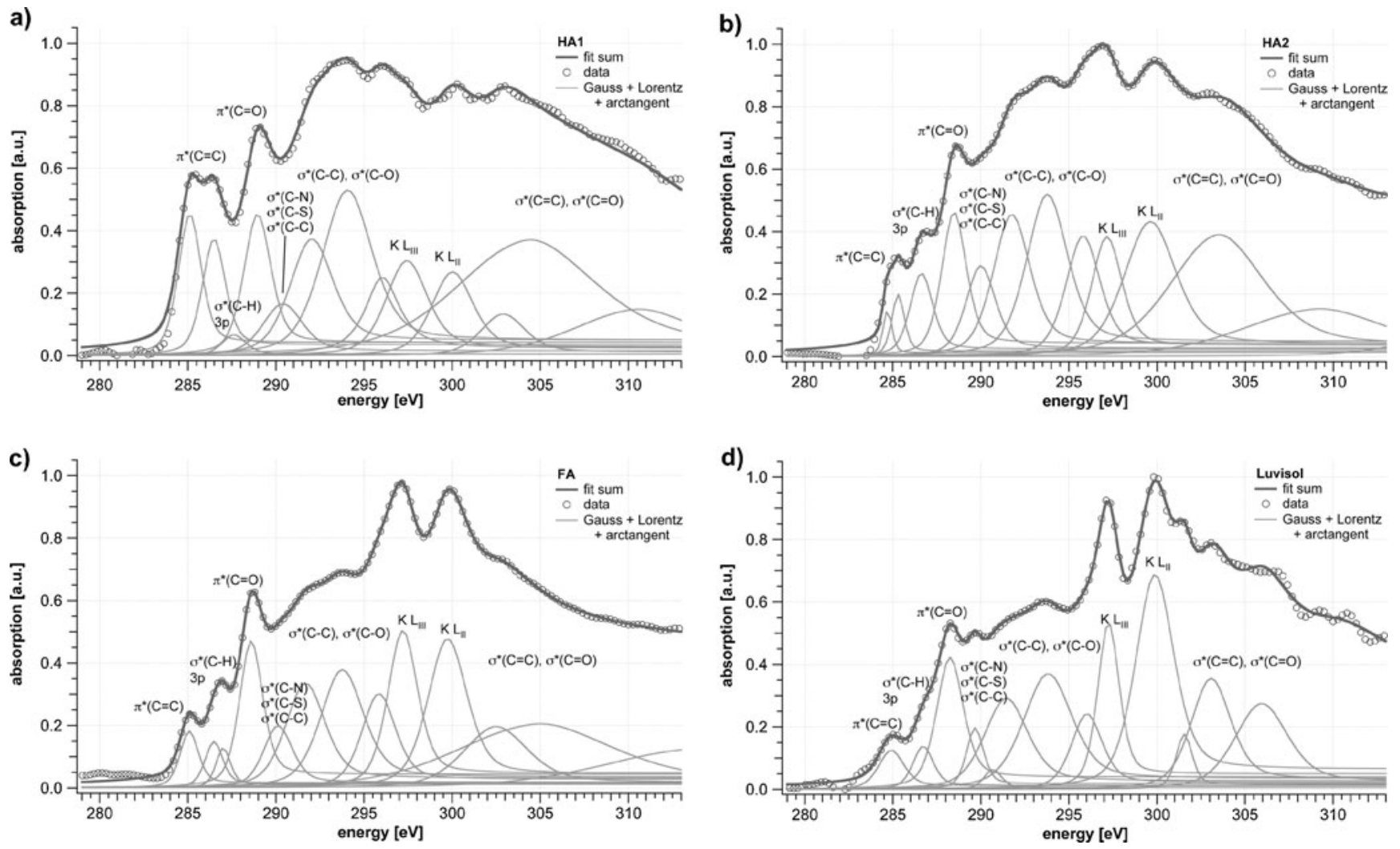

Fig. 4 Result of NEXAFS spectroscopy on four different samples: a HA1 (extracted with $\mathrm{NaOH}$ from a gleyic chernozem soil sample), b HA2 (extracted with $\mathrm{NaOH}$ from same chernozem soil sample), c FA

the benzene and phenolic peaks are located - the area under the two Gaussian curves is $22.8 \%$. The strong carbon signal masks the two potassium peaks resulting from the $\mathrm{L}_{\mathrm{III}}$ and $\mathrm{L}_{\text {II }}$ absorption edges. HA2 shows a high aromatic and phenolic content, together $14.1 \%$, but the ratio of carbonyl/ carboxyl to these groups is more in favor of the $\mathrm{COO}(\mathrm{H})$ groups than in the first sample in Fig. 2a; with $11.3 \%$ alone, the peak, around $288.1 \mathrm{eV}$, is much higher than the ones at 285 and $286 \mathrm{eV}$. The spectral features of the reference HA (see Fig. 2) resemble HA1 more closely.

The spectrum of the sample depicted in Fig. 4c yielded the results we expected from an FA (Bubert et al. 2000; Frimmel et al. 2002), in particular the low carbon content, observable from the smaller peaks around $285-286 \mathrm{eV}$ (9.27\%) and the high $\pi^{*}{ }_{\mathrm{C}=\mathrm{O}}$ resonance at $288.1 \mathrm{eV}$ (17.0\%). Comparing the results in Figs. 3 and 4 from the samples HA, HA1, and HA2, to the FA the content of carboxylic groups is with $17.0 \%$ of the peak areas highest for the FA. This coincides with chemical analysis (Stevenson 1994). In general, FA of aqueous origin contain relatively less carbon than samples extracted from soils, which means that more oxygen and other atoms are incorporated in the FA molecules. This has been proved by other authors with several other methods. The FA has also been studied using XPS (Bubert et al. 2000). The peak

of aquatic origin, and $\mathbf{d}$ unfractionated luvisol soil. The resulting elemental compositions are listed in Table 1, and the peak assignments for luvisol are also collated in Table 2

assignments and also the way of calculating the elemental composition are in good accordance to the results reported here.

To show that whole soil samples without being extracted or processed by other preparation technique can be investigated, too, we chose the Ah-horizon of a luvisol under agricultural use; the corresponding NEXAFS spectrum is presented in Fig. 4d. This type of soil contains a high amount of clay minerals, and other inorganic materials. The overall content of organic carbon is around $2.5 \%$ in the studied soil layer (Ahl et al. 2007). Here, the $\pi^{*}{ }_{\mathrm{C}=\mathrm{O}}$ peak (carbonate) in the NEXAFS spectrum is prominent, and the aromatic peak appears to be the lowest of all four samples. We assume this high peak is due to liming of the soil, a common practice to increase its fertility. Owing to the low carbon content and higher content of illitic materials of the luvisol, the resonances of the $\mathrm{K} \mathrm{L}_{\text {II,III }}$ edges are particularly high in this spectrum.

The spectra are comparable to those achieved with synchrotron radiation (Solomon et al. 2005, 2009; Schumacher et al. 2005), as they exhibit the expected peaks at the characteristic positions. This could provide the possibility to perform test experiments with samples, which are later studied in more detail with X-rays generated by a storage ring and might as well give an impulse on the broader spread of the 
application of NEXAFS spectroscopy. Nonetheless, due to the setup of the instruments, the recorded spectra only give information about the averaged sample, and of course, the source does not reach the brilliance of a synchrotron. Spatial resolution, as for instance provided by spectromicroscopy, cannot be expected. Furthermore, the grating does not allow for a spectral resolution better than $0.2 \mathrm{eV}$ in the energy range that was used for the experiments here.

\section{Conclusions and outlook}

We presented a NEXAFS spectrometer with a compact $\mathrm{x}$ ray source, together with a new approach to analyze the data. Using a lab-based instrument with a compact X-ray source, NEXAFS spectra of heterogeneous environmental samples were recorded. The spectra of the extracted HA and FA are in well congruence with data of similar samples obtained at synchrotrons reported in the literature. It was even possible to record a spectrum of a whole soil sample, without further extraction or preparation. Yielding reliable and reproducible results, such tabletop instruments could thus serve as a complementary technique to test and prepare synchrotron-based NEXAFS experiments, sometimes even as an alternative, if not too detailed spectra are necessary. The analysis uses a new approach to fit the NEXAFS spectra, by introducing a "valence band" for every peak represented as arctangent for every resonance, thereby taking the heterogeneity of the samples into account. From the analysis, quantitative statements about the elemental composition and even the relative amount of the binding types were made.

In addition to the experiments presented here, there is still potential to increase the scope of application of the NEXAFS technique. The setup allows for surface-specific measurements, since it is possible to study the samples in reflection mode, too (Peth et al. 2008). In that mode, the formation of organic coatings on mineral substrates could be directly observed. Additionally, other elements like potassium are detectable, and it should be possible to gain more information on their chemical environment, e.g., different illites.

We described the sample preparation as straightforward and noninvasive, but only for dry samples. Despite of that, it is also manageable to study wet or anoxic samples, if a small droplet or amount of the sample is enclosed between two $\mathrm{Si}_{3} \mathrm{~N}_{4}$ foils and then sealed with lacquer or glue, thereby building a small wet chamber. In addition, the spectral range of $\mathrm{Kr}$, the target gas, extends between 260 and $800 \mathrm{eV}$. That way it would also be possible to study the $\mathrm{Ca}$ signature $\left(\mathrm{L}_{\text {II, III }}\right.$ between 345 and $350 \mathrm{eV}$ ) of soil samples or the interaction of refractory organic substances (ROS) and mineral particles in general. Furthermore, by applying other filters or sample holders, information about the N K edge and $\mathrm{Fe} \mathrm{L}_{\mathrm{II}, \mathrm{III}}$ edges could be gained.
Currently, the number of compact laser-driven X-ray sources for spectrometers (and microscopes) is small but increasing. Due to this and instrumental developments, a higher throughput of interesting samples directly in the laboratory of an institute can be envisioned - at the moment with experimenting times of approximately five samples per hour. The experiments presented here demonstrate clearly what experiments with compact X-ray sources are already feasible and how to proceed with the resulting data.

Acknowledgments This work has been supported by the DFG within the Collaborative Research Center SFB 755 "Nanoscale Photonic Imaging" within project B5 (X-Ray Spectromicrosopy of Biomolecular Matter in the Environment).

Open Access This article is distributed under the terms of the Creative Commons Attribution Noncommercial License which permits any noncommercial use, distribution, and reproduction in any medium, provided the original author(s) and source are credited.

\section{References}

Ahl C, Becker KW, Jörgensen RG, Wildhagen H (2007) Aspekte und Grundlagen der Bodenkunde. Eigenverlag, Germany

Bâldea I, Schimmelpfennig B, Plaschke M, Rothe Jm Schirmer J, Trofimov AB, Fanghänel T (2007) C 1s near edge X-ray absorption fine structure (NEXAFS) of substituted benzoic acids - a theoretical and experimental study. J Electron Spectrosc 154:109-118

Benzerara K, Menguy N, López-García P, Yoon T-H, Kazmierczak J, Tyliszczak T, Guyot F, Brown GE (2006) Nanoscale detection of organic signatures in carbonate microbialites. PNAS 103 (25):9440-9445

Boese J, Osanna A, Jacobsen C, Kirz J (1997) Carbon edge XANES spectroscopy of amino acids and peptides. J Electron Spectrosc 85(1-2):9-15

Brandes JA, Lee C, Wakeham S, Peterson M, Jacobsen C, Wirick S, Cody G (2004) Examining marine particulate organic matter at sub-micron scales using scanning transmission X-ray microscopy and carbon X-ray absorption near edge structure spectroscopy. Mar Chem 92:107-121

Braun A (2005) Carbon speciation in airborne particulate matter with C (1s) NEXAFS spectroscopy. J Environ Monit 7(11):1059-1065

Braun A, Wirick S, Kubátová A, Mun BS, Huggins FE (2006) Photochemically induced decarboxylation in diesel soot extracts. Atmos Environ 40(3):5837-5844

Braun A, Huggins FE, Kubátová A, Wirick S, Mariq MM, Mun BS, McDonald JD, Kelly KE, Shah N, Huffmann GP (2007) Toward distinguishing woodsmoke and diesel exhaust in ambient particulate matter. Environ Sci Technol 42(2):374-380

Bubert H, Lambert J, Burba P (2000) Structural and elemental investigations of isolated aquatic humic substances using X-ray photoelectron spectroscopy. Fresen J Anal Chem 368(2):274-280

Cody GD, Botto RE, Ade H, Behal S, Disko M, Wirick S (1995) Innershell spectroscopy and imaging of a subbituminous Coalin-situ analysis of organic and inorganic microstructure using $\mathrm{C}$ (1s)-NEXAFS, Ca (2p)-NEXAFS, and C1 (2s)-NEXAFS. Energy Fuel 9(3):525-533

Cody GD, Ade H, Wirick S, Mitchell GD, Davis A (1998) Determination of chemical-structural changes in vitrinite accom- 
panying luminescence alteration using C-NEXAFS analysis. Organ Geochem 28(7-8):441-455

Cooney R, Urquhart S (2004) Chemical trends in the near-edge X-ray absorption fine structure of monosubstituted and parabisubstituted benzenes. J Phys Chem B 108(47):18185-18191

CXRO (2010) Website: http://henke.lbl.gov/optical_constants/atten2. html, retrieved 10-03-2010

CXRO (Center for X-Ray Optics) and ALS (Advanced Light Source) (2009) X-Ray Data Booklet. http://cxro.lbl.gov/x-ray-data-booklet

Dhez O, Ade H, Urquhart S (2003) Calibrated NEXAFS spectra of some common polymers. J Electron Spectrosc 128:85-96

di Stasio S, Braun A (2006) Comparative NEXAFS study on soot obtained from an ethylene/air flame, a diesel engine, and graphite. Energy Fuel 20(1):187-194

Fiedorowicz H (2005) Generation of soft X-rays and extreme ultraviolet (EUV) using a laser-irradiated gas puff target. Laser Part Beams 23(3):365-373

Francis JT, Hitchcock AP (1992) Inner-shell spectroscopy of $p$ benzoquinone, hydroquinone, and phenol: distinguishing quinoid and benzenoid structures. J Phys Chem 96(16):6598-6610

Frimmel FH, Abbt-Braun G, Heumann GK, Hock B, Lüdemann H-D, Spiteller M (eds) (2002) Refractory organic substances in the environment, 1 st edn. Wiley-VCH, Weinheim

Gleber G, Thieme J, Niemeyer J, Feser M (2003) Interaction of organic substances with iron studied by O1s spectroscopydevelopment of an analysis program. J Phys IV 104:3153-3168

Hertz HM, Bertilson M, Chubarova E, Ewald J, Gleber S-C, Hemberg $\mathrm{O}$, Henriksson M, v Hofsten O, Holmberg A, Lindblom M, Mudry E, Otendal M, Reinspach J, Schlie M, Skoglund P, Takman PA, Thieme J, Sedlmair J, Tjörnhammer R, Tuohimaa T, Vita M, Vogt U (2009) Laboratory x-ray micro imaging: sources, optics, systems and applications. J Phys IV 104:012027

Hitchcock A (2009) Website: Gas Phase Core Excitation Database. http://unicorn.mcmaster.ca/corex/cedb-title.html, retrieved 10-022009

Hitchcock A, Morin C, Zhang X, Araki T (2005) Soft X-ray spectromicroscopy of biological and synthetic polymer systems. J Electron Spectrosc 144-147:259-269

Huffman G, Mitrea S, Huggins F, Shah N, Vaidya S, Lu F (1991) Quantitative analysis of all major forms of sulfur in coal by x-ray absorption fine structure spectroscopy. Energ Fuel 5(4):574-581

Ishii I, Hitchcock AP (1987) A quantitative experimental study of the core excited electronic states of formamide, formic acid, and formyl fluoride. J Phys Chem 87(2):830-839

Ishii I, Hitchcock A (1988) The oscillator strengths for C1s and O1s excitation of some saturated and unsaturated organic alcohols, acids and esters. J Electron Spectrosc 46(1):55-84

Jansson PAC, Vogt U, Hertz HM (2005) Liquid-nitrogen-jet laserplasma source for compact soft x-ray microscopy. Rev Sci Instrum 76:043503

Kaznacheyev K, Osanna A, Jacobsen C, Plashkevych O, Vahtras O, Ågren H, Carravetta V, Hitchcock A (2002) Inner-shell absorption spectroscopy of amino acids. J Chem Phys 46(106):55-84

Kikuma J, Tonner BP (1996) XANES spectra of a variety of widely used organic polymers at the CK-edge. J Eletron Spectrosc 82(12):53-60

Kolczewski C, Püttner R, Martins M, Schlachter AS, Snell G, Sant'anna MM, Hermann K, Kaindl G (2006) Spectroscopic analysis of small organic molecules: a comprehensive near-edge $\mathrm{x}$-ray-absorption fine-structure study of C6-ring-containing molecules. J Chem Phys 124(3):034302

Lehmann J, Kinyangi J, Solomon D (2007) Organic matter stabilization in soil microaggregates: implications from spatial heterogeneity of organic carbon contents and carbon forms. Biogeochemistry 85:45-57
Mitrea G, Thieme J, Guttmann P, Heim S, Gleber S (2008) X-ray spectromicroscopy with the scanning transmission X-ray microscope at BESSY II. J Synchrotron Radiat 15(1):26-35

Monteil-Rivera F, Brouwer E, Masset S (2000) Combination of X-ray photoelectron and solid-state ${ }^{13} \mathrm{C}$ nuclear magnetic resonance spectroscopy in the structural characterization of humic acids. Anal Chim Acta 424:243-255

Nováková E, Mitrea G, Peth C, Thieme J, Mann K, Salditt T (2008) Solid supported multicomponent lipid membranes studied by $\mathrm{x}-$ ray spectromicroscopy. Biointerphases 3(2):44-54

Pagel-Wieder S, Niemeyer J, Fischer WR, Gessler F (2007) Effects of physical and chemical properties of soils on adsorption of the insecticidal protein (Cry1Ab) from Bacillus thuringiensis at $\mathrm{Cry} 1 \mathrm{Ab}$ protein concentrations relevant for experimental field sites. Soil Biol Biochem 39(12):3034-3042

Peth C (2008) XUV-Laserplasmaquellen für die AbsorptionsSpektroskopie und zeitaufgelöste Röntgenbeugung, PhD-Thesis. Georg-August-University, Göttingen

Peth C, Barkusky F, Mann K (2008) Near-edge x-ray absorption fine structure measurements using a laboratory-scale XUV source. J Phys D Appl Phys 41(10):105202

Plucinski P, Gorski Z, Slawinski J (2007) Resistance of model humic acids to ultraviolet-c radiation. Acta Agrophysica 9:191-202

Rehr JJ, Albers RC (2000) Theoretical approaches to x-ray absorption fine structure. Rev Mod Phys 72(3):621-654

Rodrigues AL, Brito AG, Janknecht P, Silva J, Machado AV, Nogueira $\mathrm{R}$ (2008) Characterization of biofilm formation on a humic material. J Ind Microbiol Biot 35(11):1269-1276

Samant M, Stöhr J, Brown H, Russell T, Sands J, Kumar S (1996) Nexafs studies on the surface orientation of buffed polyimides. Macromol 29(26):8334-8342

Schäfer T, Buckau G, Artinger R, Kim JI, Geyer S, Wolf M, Bleam WF, Wirik S, Jacobsen C (2005) Origin and mobility of fulvic acids in the Gorleben aquifer system: implications from isotopic data and carbon/sulfur XANES. Organ Geochem 36(4):567-582

Scheffer F, Schachtschabel P (2010) Lehrbuch der Bodenkunde, 16th edn. Spektrum

Schumacher M, Christl I, Scheinost A, Jacobsen C, Kretzschmar R (2005) Chemical heterogeneity of organic soil colloids investigated by scanning transmission X-ray microscopy and C-1s NEXAFS microspectroscopy. Environ Sci Technol 39:9094-9100

Sedlmair J, Gleber S-C, Peth C, Mann K, Thieme J (2009) NEXAFS spectroscopy with a laser plasma $\mathrm{X}$-ray source on soil samples. J Phys IV 104:012034

Seres J, Yakolev VS, Seres E, Streli C, Wobrauschek P, Spielmann C, Krausz F (2007) Coherent superposition of laser-driven soft-Xray harmonics from successive sources. Nat Phys 3:878-883

Sham TK, Yang BX, Kirz J, Tse JS (1989) K-edge near-edge x-rayabsorption fine structure of oxygen-and carbon-containing molecules in the gas phase. Phys Rev A 40(2):652-669

Shober AL, Hesterberg DL, Sims JT, Gardner S (2006) Characterization of phosphorus species in biosolids and manures using XANES spectroscopy. J Environ Qual 35(6):1983

Sierra MMD, Giovanela M, Parlanti E, Esteves V, Duarte A, Fransozo A, Soriano-Sierra E (2005) Structural description of humic substances from subtropical coastal environments using elemental analysis, FT-IR and ${ }^{13} \mathrm{C}$-solid state NMR data. J Coast Res 42:370-382

Singh B, Gräfe M (eds) (2010) Developments in soil sciencesynchrotron-based techniques in soils and sediments. Elsevier, Amsterdam

Smith AP, Urquhart SG, Winesett DA, Mitchell G, Ade H (2001) Use of near edge X-ray absorption fine structure spectromicroscopy to characterize multicomponent polymeric systems. Appl Spectrosc 55(12):1676-1681 
Solomon D, Lehmann J, Kinyangi J, Liang B, Schäfer T (2005) Carbon K-edge NEXAFS and FTIR-ATR spectroscopic investigation of organic carbon speciation in soils. Soil Sci Soc Am J 69(1):107-119

Solomon D, Lehmann J, Kinyangi J, Liang B, Heymann K, Dathe L, Hanley K, Wirick S, Jacobsen C (2009) Carbon (1s) NEXAFS spectroscopy of biogeochemically relevant reference organic compounds. Soil Sci Soc Am J 73(6):1817

Stevenson FJ (1994) Humus chemistry: genesis, composition, reactions, 2nd edn. Wiley, New York

Stöhr J (1992) NEXAFS spectroscopy. Springer, Berlin

Stöhr J, Samant MG, Luning J, Callegari AC, Chaudhari P, Doyle JP, Lacey JA, Lien SA, Purushothaman S, Speidell JL (2001) Liquid crystal alignment on carbonaceous surfaces with orientational order. Science 292(5525):2299-2302

Thieme J, Sedlmair J, Gleber SC, Prietzel J, Coates J, Eusterhues K, Abbt-Braun G, Salome M (2010) X-ray spectromicroscopy in soil and environmental sciences. J Synchrotron Radiat 17(2):149-157
Urquhart S, Ade H (2002) Trends in the carbonyl core (C 1s, O $1 \mathrm{~s}) \rightarrow \pi^{*} \mathrm{C}=\mathrm{O}$ transition in the near-edge $\mathrm{X}$-ray absorption fine structure spectra of organic molecules. J Phys Chem B 106 (34):8531-8538

Vogt U, Frueke R, Wilhein T, Stollberg H, Jansson PAC, Hans Hertz HM (2004) High-resolution spatial characterization of laser produced plasmas at soft X-ray wavelengths. Appl Phys B 78:53-58

Wang Y, Granados E, Larotonda MA, Berrill M, Luther BM, Patel D, Menoni CS, Rocca JJ (2006) High-brightness injection-seeded soft X-ray-laser amplifier using a solid target. Phys Rev Lett 97:123901

Xia K, Weesner F, Bleam WF, Helmke PA, Bloom PR, Skyllberg UL (1998) XANES studies of oxidation states of sulfur in aquatic and soil humic substances. Soil Sci Soc Am J 62:1240-1246

Zepf M, Dromey B, Landreman M, Foster P, Hooker SM (2007) Bright quasi-phase-matched soft-X-ray harmonic radiation from argon ions. Phys Rev Lett 99:143901 